

\title{
Interpersonal Relations as a Tool to Film Directing
}

\author{
Caio Augusto Camargo Bogoni \& Renate B. Michel
}

\section{Introduction}

A classic reflection ponders if art imitates life or if life imitates art. Aristotle defends the former, Oscar Wilde the latter. Art, in any form it presents itself, is intimately connected to human feelings. Naturally, being a form of human expression, it has the potential to touch people in a deeper level than the frequently superficial daily relations do.

Cinema tells stories about big and small people, old times and those yet to come; it explores life from the most peaceful suburb to the spectacle of space expeditions. Every story has the potential to convey meanings and awaken feelings in those who experiment it, but this is a universal attribute of every story. A book can tell a story as can a song or a symphony, while there is a unique approach regarding cinema: actors are necessary to play and portray the work's themes. Not only them but also a whole team is involved in the production of a movie. Screenwriters, dramatists, choreographers, sound designers and makeup artists also participate, as well as costume designers, editors, musicians and other artists (Rabiger, 2008).

Despite the production's scale, which is directly connected to the budget, the director is in charge of coordinating a team and of making the best of them. Rabiger (2008) asserts that the director is responsible for the quality, details and meaning of the film. He must work with writers; envision the film's scope, purpose and identity; arrange auditions and cast actors; develop crew and script; and ultimately supervise finalization of the project.

Directing a movie means more than sharing workspace with other people, the director is connected to all of the work being produced. Be it supervising or getting directly involved, he must have knowledge in practice and theory, but not only that: it is equally important to have a broad 
repertoire of social skills. An effective intervention must consider deeper principles than speaking on the imperative and giving orders away.

Ideally, Rabiger (2008) characterizes the director as a person that can be articulate and succinct in his/her communication, make instinctive judgments and decisions, extract the best of his/her team without being a tyrant, speak respectfully with specialists and comprehend technical problems to better embrace their efforts. Salvi (2003) points out that this profession is more dependent of personal qualities than any other is. Any problems and personal matters that the director brings to the set will have consequences, as his object of work is the human being and the elements that comprise it.

This work seeks to illustrate how the director can use knowledge in psychology to develop helpful skills to his/her work on the set. Psychology and art share the human being as the fundamental object of work; they use it as a source of reflection and consideration. Despite being different areas of study, they are not as distant as they may seem. Art highlights life and makes people reconnect with the common bond that helps to solve the isolation that everybody suffers from. (Salvi, 2003) Likewise, a group therapist, the director is in charge of a group's maintenance and must be conscious of the psychological phenomena involved. Subjacent to technical considerations, there must be a consistent and positive relationship between the leader and his team. The basic stance of the former towards the latter must be rooted in interest, acceptance, genuineness and empathy. No technical consideration has precedence over these attitudes. (Yalom, 2006)

\section{The Ideal Director}

Perfection. Sought by many, it is an immaculate state of nature immune to critics and flaws because it is an end in itself. With an indisputable status of grandiosity, a perfect person does not need the hunches and opinions of the world. With that being said, the idea behind an ideal model 
of director is not to instigate a quest for an unreachable objective, but to show elementary qualities and fields of knowledge considered important to the profession. More than indicate an objective, this model's purpose is to encourage awareness and self-development.

Elia Kazan (2009) introduces a series of qualities and fields of knowledge deemed necessary for those who seek to be a filmmaker. Practically every field minimally connected to cinema is cited, including many others that do not seem to be close at first glance, but eventually show their relevance.

A director should know literature of all kinds and periods. He/she will be better equipped if he/she is well read. Additionally, classic theatre literature provides knowledge on structure, characterization, theme exposition and construction of a unity pointing to a climax. A director must know screenwriting in order to guide rewrites and eliminate what is unnecessary, correct flaws, appreciate non-verbal possibilities and have a sense of a scene's screen time, place and purpose. (Kazan, 2009)

To a greater or lesser extent, all of the aforementioned areas are connected to cinema somehow. Since it involves cooperation between many professionals of different areas, it is possible to establish bridges between the author's recommendations and roles in a movie production. Knowing how to tell a joke and anticipate laughter, for example, can be essential to those interested in making comedy films. Similarly, acrobatics, juggling and dancing can be connected to the musical genre because its singing and dancing numbers demand knowledge on how to manipulate and arrange people according to rhythm and synchrony. Furthermore, Kazan (2009) argues that dancing is a great advantage because it allows one to know how to move. Consequently, it helps the director to move not only the actors but the camera as well. 
Painting, sculpture, colors and knowledge of one's own city can be connected to production design, an area responsible for the film's general visual representation. Because set composition encompasses so many spheres of visual arts, it can also be associated to stage scenery, also mentioned by Kazan (2009). Related to cinematography — photography applied to cinema - it is possible to emphasize the mention of lighting and how it affects mood and behavior; also the camera and lenses, the effects created by them, which may lie or reveal the harsh truth. (Kazan, 2009)

Addressing psychology, Kazan (2009) highlights the importance of normal and abnormal behavior - terms used by the author. A connection between these two types is pointed out: one is an extension or intensification of the other. More importantly, it is up to the director to understand the difference between movement and psychology. Directing can be understood as the conversion of psychology into behavior. Cinema deals with images and sounds. Psychic content, while very real, is not visible from the outside. Fear, affection, anxiety, anguish, and happiness are all essential parts of the human experience. Art seeks to create feelings like these in the public, strong and lasting impressions through concrete and palpable representations that can be experienced by other people. The artist must externalize the invisible in order to work with psychology in a broad sphere. Kazan (2009) points out the importance of knowing the difference between the psychology of the audience and individual psychology.

Concerning the psychology of the audience, Salvi (2003) expresses ideas of identification and empathy. It is easier for the public, exposed to artistic material, to identify with a character when it touches a universal point. Emotions are universal and the actor is the key to achieving them because he/she is responsible for making the script come alive. Additionally, Glebas (2003) affirms that the director conducts the attention of the audience through arrangements of images and sounds. First, he/she captures the audience's attention, and then protects it from distractions. 
Regarding individual psychology, this can be interpreted as one's personality: a set of psychical traits and individual experiences. These aspects, discussed more profoundly in works about typology, can be used in character construction when writing a script, for example.

A complete repertoire is essential because direction is total. Basic decisions are left to the director and, while it is not his/her job to execute them, he/she must know enough about each area to point to the right direction and know how to ask the right questions. (Kazan, 2009) He/she does not do other people's work; his/her task is to guide cooperative efforts towards the same goal: fulfill the director's vision.

The director, in turn, has a commitment with the story and the audience. He/she must represent the themes of the former and illustrate it using images for the latter. Full responsibility for the process of filmmaking must be taken. It is a great obligation, but not a burden. Those are the rules of the game the director chose to play. (Kazan, 2009) Salvi (2003), who reiterates the importance of the director admitting when he/she is wrong, supports this notion of responsibility. Alternatively, mistakes can be treated as experiments. Sometimes, the problem is not the idea behind the direction given, but the way it was verbalized. When the director takes responsibility, actors feel supported and there is a sense of cooperation. They will do what the director wants if they feel he/she can guide them, be honest and take full responsibility while being open to ideas and feelings. (Salvi, 2003)

Salvi (2003) discusses the actor's profession relation with the market and the way it influences the relationship with the director. Because the profession offers no stability, actors must prove their worth repeatedly, leaving them in a perpetual state of insecurity, vulnerable and sensitive to criticism. It is up to the director to be aware of how to give feedback and take responsibility for ill-fated decisions. 
More than all these fields, Kazan (2009) states that the director must know one especially well, to the smallest detail, and unforgivably appreciate the ambivalences at play: himself. Among the ways of working on this aspect, it is possible to find a possible useful solution in psychotherapy, which develops and stimulates self-knowledge. According to Jung (2011), disunity with oneself is the neurotic condition par excellence, unbearable and undesirable for the individual. In the words of the author: "nothing is as difficult as tolerating oneself." (Idem). As mental health is an unavoidable step in the process of self-knowledge, aiming for a state of psychical health and harmony cannot be a bad idea for someone who aims to become a film director. Thus, uniting selfknowledge with the aspiration of professional development can yield better results, since selfknowledge without the impulse of external necessity is inefficient even when the subject is deeply convinced of its truth. (Jung, 1954)

According to Jung (1954), a person interested in being a therapist cannot do his/her job well without knowing his/her own unconscious processes. Drawing a parallel with a director interested in knowing himself/herself better, the statement is still valid. Thus, the director's quest to hone his/her self-knowledge is a natural activity of the profession, not entirely arbitrary. Jung (1954) argues that the individual's concern with the unconscious cannot be explained entirely by the free choice of interests, but by the unavoidable disposition that inclined him/her to follow this path.

Similarly, Salvi (2003) describes self-knowledge, in general terms, as an essential tool for a talented actor. According to the author, talented actors have the following characteristics: they are in touch with their own feelings and perceptions; in tune with the environment; receptive to the effect of people, places and sensory stimuli on themselves; and imagination, moreover a willingness to express it. Therefore, it is something to be used not only by the director, but also by the actor and possibly by any artist. 
When discovering new horizons within the psyche, revealing the existence of qualities and capacity for development, there is also the possibility of recognizing personal limits. Regarding these, Jung (1954) states that it is best to always be aware of one's own knowledge and skill. Kazan (2009) states that the best way to acquire the aforementioned knowledge is through practice. Acting onstage is more useful than reading about acting and studying the advices of a great teacher.

Kazan (2009) cites knowledge with little or no apparent connection to cinema, such as knowledge of climate or of erotic arts through personal experience. Concerning these choices, the author justifies that nothing is irrelevant or trivial. The director's life is an infinite source of material. Every experience leaves its residue of knowledge behind. Everything heard and seen can be stolen if it is appreciated. (Kazan, 2009)

Life experience always aggregates content and can be used in countless ways by artists that express their personal experiences, personality idiosyncrasies and worldview through their work. Choosing an actor for a role, for example, is a task aided by seemingly harmless practices. Starting from intuition, Kazan feels an answer coming from an actor and invites him to a walk and talk about the most varied subjects. The chitchat about love, marriage, nationality and family reveals why there was that peculiar response. The actor must be capable of moving the director somehow. (Kazan, 2009) Similarly, Salvi (2003) brings intuition as a tool that can also be used by the actor. When active, the actor has a deep and spontaneous connection with the soul of the character. Therefore, the same person responsible for moving the audience must also be able to reach his/her director.

As for personal characteristics and qualities that a director must foster, the person one must train oneself to become, Kazan (2009) points out a series of analogies and attributes of the most varied types. Because of their specific and metaphorical nature, they are in the author's own words. 
A foreman who knows the problems, their solutions and is, therefore, prepared to insist on them. A psychoanalyst who maintains a functional patient in spite of intolerable tensions and stresses [...]. A poet, a poet of the camera. [...].The cunning of a trader in a Baghdad bazaar. The firmness of an animal trainer. [...]The kindness of an old-fashioned mother who forgives all. The authority and sternness of her husband, the father, who forgives nothing, expects obedience without question, brooks no nonsense. And these alternatively: The elusiveness of a jewel thief — no explanation, take my word for this one. The blarney of a PR man [...]. A very thick skin. A very sensitive soul. Simultaneously. [...]An unwavering refusal to take less than he thinks right out of a scene, a performer, a co-worker, a member of his staff, himself. Direction, finally, is the exertion of your will over other people — disguise it, gentle it, but that is the hard fact. Above all COURAGE. Courage, said Winston Churchill, is the greatest virtue; it makes all the others possible. One final thing: the ability to say "I am wrong," or "I was wrong." Not as easy as it sounds. But in many situations, these three words, honestly spoken, will save the day. (Kazan, 2009, position 4485)

\section{Empathy}

Keeping in mind all areas of knowledge and features suggested as important to a successful director, there are some essentially personal areas that can be developed. Among them, interpersonal skills are an elementary part because cinema deals precisely with the communication between an artist — or a team of them — and their audience. However, even before this latter part enters the equation, the director must know the value of efficient, assertive and objective communication in order to convey his/her vision as clearly as possible, as well as recognize the demands of his/her team. 
The beginning of a genuine interpersonal relationship occurs through a basic artifice: empathy. Although it seems straightforward to put oneself in another's shoes, it is not always an easy task, because it involves withdrawing partially from the interaction to make room for the other's feelings and needs. Judgments, beliefs, opinions, and personal inferences go out of play so that there is a more attentive perception of the content brought by the other person.

As other arts, the essence of cinema is the reflection of the human condition. An artist shares his/her humanity with the rest of the world. He/she makes the audience laugh and cry, fills them with excitement and can make them experience the intimate life of another person and, through that, discover unifying bonds. An artist needs awareness, empathy, a point of view and the tools to express it. (Salvi, 2003) In consonance with the theme, Rosenberg (2006) highlights the difficulty involved in self-expression, since it involves revealing thoughts and needs. The key to this situation arises when one is in empathy with others, so that one can touch their humanity and perceive the shared qualities.

As other arts, the essence of cinema is the reflection of the human condition. An artist shares his/her humanity with the rest of the world. He/she makes the audience laugh and cry, fills them with excitement and can make them experience the intimate life of another person and, through that, discover unifying bonds. An artist needs awareness, empathy, a point of view and the tools to express it. (Salvi, 2003) In consonance with the theme, Rosenberg (2006) highlights the difficulty involved in self-expression, since it involves revealing thoughts and needs. The key to this situation arises when one is in empathy with others, so that one can touch their humanity and perceive the shared qualities.

Because it involves the expression and representation of unmistakably human feelings, emotions and behaviors, to be emotionally disconnected is a critical issue according to Salvi 
(2003). Experiencing the feelings of others and sharing oneself with them makes the magic happen. The greater the connection with feelings and needs behind other people's words, the less frightening it is to open up to them. (Rosenberg, 2006)

Without empathy, how can a director or actor create characters that touch the audience? It provides more than unity within the cast, as it allows the perception of elements that can interfere with teamwork and, more importantly, helps the director to notice when others need him. Through the experience of the other, problems that may hinder the execution of a scene become evident. Paying attention to the situation with his inner eye and ear, the director can listen to the words and deduce its subtext. If an aerial mind is the result of this examination, the scene is devoid of something, it is empty. (Salvi, 2003)

Rosenberg (2006) talks about the importance of intervening when something wrong is noted in another person's speech. Contextualizing, a tiresome conversation can be considered equivalent to insipid acting. In a situation where the director is faced with an unsatisfactory performance, he/she must know when and how to cut off the action so that the actor can be guided. With this in mind, Rosenberg (2006) suggests that the right moment to interrupt is right when the first undesirable trait occurs in the interaction. This immediate interruption enables the subject to connect with the vital energy of the words and deeds. In the context of cinema, this intervention would allow the actor to bond more to the role and its demands, as well as to his own experience in order to use it as a repertoire for credible performances. As in Stanislavski's words (2015: 25): "To reproduce feelings, you must be able to identify them in your own individual experience." Film directing involves dealing with feelings. Therefore, although many people are conditioned to repress and hide them, self-knowledge is important because it is impossible to empathize with something without recognizing the feelings within. (Salvi, 2003) 
Rosenberg (2006) proposes that, as listeners, one needs no insights into psychological dynamics or training in psychotherapy. The ability to be present in what happens inside the other person, their unique feelings and needs, is essential. However, Salvi (2003) proposes a more practical solution when she discusses one of her most defended principles: rehearsals. In them, it is possible to establish rapport and a sense of trust and cooperation between the team, as well as to learn how each individual works and their individual needs.

To be encouraging and warm rather than rude and patronizing makes a difference. Over time, good intentions can fade and make room for animosity with no apparent cause. Actually, there is one: lack of tact in communication. (Salvi, 2003) As an unseen plague, the actor's decaying involvement with his/her role — albeit affected by fatigue and repetition - undermines the possibilities of a genuine involvement between the audience and the film. Ultimately, the actor breaks the empathic chain among character, actor and audience. The director must have the confidence to trust his/her intuition and identify the problem, but that is not enough. He/she still needs to offer a solution to the situation so everyone can move forward.

\section{Objectivity and Assertiveness}

With empathy well established, the relationship between the director and his team becomes deeper and more aware of each situation's demands. However, it can also be supplemented by other abilities. Objective communication establishes a channel of clear and direct information, conducting towards an objective that is interesting for the director and, consequently, towards an accessible representation of the story to the audience. One of these qualities is objectivity in discourse, whether it is giving instructions or feedback to the team. 
The challenge is to communicate a concept in palpable and accessible terms, avoiding long and intellectualized speeches so the actors' imaginations are not dulled. Walking a path without clarity brings confusion to the cast, who will then become self-conscious of their efforts if communication continues to fail. (Salvi, 2003) The first step is to embrace empathy, which is essential for the director because it prevents him from speaking without being aware of what others are feeling, needing or asking for. Redundant and verbose communication turn the listener into a garbage basket of words. (Rosenberg, 2006)

The picture of a long speech full of unnecessary information says enough. The listener will have to make an extra effort to process the higher amount of words spoken and then select which are very useful. Not only that, as there is the risk of inefficient explanations provoking interpretations or conclusions different from those intended. Accurate communication prevents time loss and new takes being plagued by undesired acting. The more specific the director is, the better. This need does not mean actors are stupid. As they are their own instrument of work, they cannot possibly watch themselves and act naturally. (Salvi, 2003).

This is not to say that the process should be rushed or take shortcuts to reach an objective faster. This practice is as unproductive as stretching out on long speeches. In a section called "Common Traps and Errors in Management", Salvi (2003) points out result-oriented directing as a form of inappropriate communication. It means skipping steps and demanding completion without development, which is the complete opposite of the director's task. His/her work is to lead the actor until the result is reached naturally. The author often emphasizes that focusing on the process that leads to the goal is the best method of reaching it. Stanislavski (2015), in turn, points out that this is also a common mistake of actors, who think about the outcome rather than the action that will lead them to it. He proposes a direction based on active verbs that express action and indicate movement. 
Communication is a key aspect of the actor-director relationship. Directing is a complex task that requires careful preparation followed by confrontation with reality. One must show the cast how well the film has been previously worked on and then direct towards the desired behavior. According to Stanislavski (2015), there are people who talk about art and creation with false emotions, in an indistinct and complicated way. True artists, on the other hand, speak in simple, understandable terms. In case a director is unclear about what he/she wants, the actors, his/her vehicles of expression, get confused and the communication fails. It is necessary to be assertive to achieve goals, and to be a strong and benevolent leader to build confidence on the set. Once convinced of it, the actors fit themselves into the desired line of thought. (Salvi, 2003)

\section{Feedback}

A common phenomenon on set, given the repetition of takes caused by the director's intervention, feedback is described by Moscovici (1997) as a process that aids behavioral changes and provides information about one's acts. In an effective way, feedback helps the individual to improve his/her performance and achieve his/her goals. Salvi (2003) states that the ability to communicate is not always what it should be because the director is not clear, does not know the correct terms or is not articulated. Without feedback, both director and actor are in trouble.

Essential feedback is: specific, for it points out a behavior on a given occasion; compatible with the needs of both giver and receiver, recapitulating the importance of empathy; directed to behaviors that the receiver can modify; provided right after the behavior in question; and clear, to ensure accurate communication. Regarding this last aspect, it is proposed that the receiver repeats the feedback to verify if the information corresponds to what the communicator wanted to say. (Moscovici, 1997) 
Competence in interpersonal relationships facilitate complex interactions, exchanges involving personal and deep content which are not always as accessible as desired. Complications can arise from the fact that each actor is a person with ambitions, dreams, desires, fantasies, fears and quirks. There may be a fear of meddling in such personal content, but it is through this subjectivity that the director gets the audience to engage in the work, as long as he/she himself/herself is engaged in the feelings of the cast. (Salvi, 2003) Interpersonal competence can be especially effective when actors are difficult to deal with, which may require greater care in managing situations resulting from their particularities. It is one of the qualities brought by Kazan (2009), who affirms that the director must be prepared and trained to deal with neurotics because most actors are. Perhaps all.

Inappropriate attitudes from the director, such as improperly transmitted feedback, can result in difficult behaviors. Like children, actors need guidance and parameters, knowing where they are being led and encouraged rather than judged. Without this, they respond with clashes, struggling emotions and loss of respect. (Salvi, 2003) Thus, acts superficially judged as immature or neurotic can be results of inadequate direction. This is not to say that difficult cases do not exist, because not everything is a direct consequence of the actions of the director.

Actors can be condescending, resistant, insecure, arrogant, argumentative, and challenging. If the acts resulting from these characteristics are taken as personal, unaccountable hurt may arise. Rosenberg (2006), reinforcing the use of empathy in such situations, states that when one reveals what lies behind another person's resistance, there is clarity of what the latter wants and what prevents him/her from responding in the desired way. When such attitudes arise, Salvi (2003) suggests rethinking who the actors are and what their lives revolve around. By seeing beyond the surface, one might discover a jewel. To be a director is more than being creative, it is being a psychologist, a diplomat, and a best friend. 
Communication between the director and his/her team is a complex relationship. Things can go wrong in many ways, thus so many cares need to be taken. In order to reach a direction consistent with the demands of the scene, the character and the story, the relationship must be based on empathy. It allows for the particularities of the individual to be exposed, highlighting possible difficulties and establishing a channel of respectful and human interaction between the two parties. Communication should be objective, straightforward, and consonant with the director's intentions. Suggestions, directions and instructions passed on without unnecessary information are more easily absorbed. Ultimately, these two elements pave the way for feedback to be communicated as efficiently as possible, also helping with complicated individuals and the problems they cause.

\section{Living the Moment}

In his book "An Actor Prepares" Konstantin Stanislavski (2015) defends the importance of creativity and inspiration as essential elements for an actor. When the actor is inspired, he/she comes in contact with his/her subconscious and the personal experiences contained there, using them as tools for the truthful interpretation of a role. Rabiger (2008) also indicates imagination as an important factor. Common in childhood — when the child imagines himself/herself in the roles of a doctor, father, mother and police officer — but lost in the self-consciousness acquired in adulthood, imagination is an element that can be trained, disciplined and encouraged.

Moments of success with the genuineness of creativity characterize the art of living a role. However, this success should not be occasional, but present in every time the scene is interpreted. (Stanislavski, 2015) After all, theater, like cinema, involves repetition. Whether it is in the performance of a play over several days or in the repeated takes of a scene, the interpretation 
must have power and truth in order to work. Unfortunately, inspiration is not something easily controllable. Actors must create under inspiration, which is provided only by the subconscious. However, apparently this subconscious can only be accessed through consciousness, which kills it. Fortunately, there are elements subject to consciousness and willpower that can activate involuntary psychic processes. (Stanislavski, 2015)

Throughout his work, the Stanislavski (2015) demystifies what these elements are and provides ways for them to be achieved. The phenomenon, which he calls sense memory, involves concentration and attention to the subject itself and to the environment, especially memories that elicit feelings similar to those demanded by the role. With this in mind, it is possible to connect Stanislavski's method to the concept of mindfulness, the mental state in which attention is directed to the present moment and all the feelings, emotions, and thoughts involved in it. Although attention and awareness are features of normal functioning, mindfulness can be defined as a state, in which the present experience or reality are lived with enhanced attention and awareness. (Brown and Ryan, 2003)

In one of Kostya's failed attempts, the protagonist of the book, he claims that he cannot detach himself from the ideas he had created on how to interpret the nature of the character he is playing. Eventually, he says he read the text by himself, played the character by himself, without relating it to the other actor on scene. (Stanislavski, 2015) Rabiger (2008) describes this phenomenon as isolation. The actor acts for himself/herself, executes the scene as planned in his/her head without reacting to the environment and to his/her fellow actors. The opposite of this process is called communion. Kostya's frustrated attempt shows he did not use mindfulness in his acting, for example, because he was focused on the circumstances in which he played the scene earlier, his home. This disconnection with the present can also happen to the director. If the director is unsure, not invested in the work, the actor is not heard and remains unsupported. To question 
oneself is to lose involvement with the scene, to stay out of it instead of immersed in it. (Salvi, 2003) It is not the actor's task alone to find himself/herself in a role. Although Stanislavski's theory talks about actors, the director participates actively in the process of achieving a satisfactory performance.

Stanislavski (2015) proposes a solution: the actor's object of attention should be on stage, in the play, in the role and in the setting. Mindfulness can be a very useful tool for that matter. As Brown and Ryan (2003) affirm, mindfulness emphasizes an open, undivided observation of what occurs internally and externally. Salvi (2003) indicates a solution to create feelings of here and now. An inner monologue — regarding the character's goals and the emulation of his/her thoughts in the scene's context, for example — can aid to the creation of depth behind the words said. It is the same solution Rabiger (2008) suggests to maintain focus and prolong the naturalness in repeated takes. Tiredness and boredom tempt the actor to take shortcuts, but maintaining the inner monologue helps him/her stay focused and live the moment.

There is a catch: Salvi (2003) states that the technique can alternatively invite the actor to intellectualize and detach himself from the scene. This would be, then, the opposite of mindfulness, which is related to the quality of consciousness, not to reflective thinking equivalent to the intellectualization of paper (Brown and Ryan, 2003). Thus, Salvi (2003) introduces another method: to verbalize physical or emotional circumstances. Its aim is to make the actor relax and rescue the naturalness, encouraging him to express and release the feeling of here and now.

Rabiger (2008) describes focus and self-awareness as the actor's heaven and hell, respectively. The author associates the former to feelings of relaxation, concentration and energy that exist when one does something one loves, and the latter to entering a room full of strangers 
and feeling weird and upset with their looks. A similar situation arises in another of Kostya's failures in Stanislavski's (2015) work. He recounts that his fears led him to feel an obligation to make the audience interested. It interfered with his focus on what he was doing, which was playing the role.

Intellectual work on set can encourage actors to stay inside their heads instead of relying on their instincts. Instructions must be linked to the plot, but repeating the plot does not yield results. (Salvi, 2003) If the director tries to force the plot's circumstances and suppositions on the actor, the result is violence. This cannot happen because the actor asks the director what he/she needs as he/she needs. (Stanislavski, 2015)

Schutz (1978) links his work to the method conceived by Konstantin Stanislavski, pointing out philosophical and practical affinities with the encounter, subject of his work. The exercises proposed by Stanislavski to release the actors' inhibition share the same purposes as the encounter. Both theories seek to develop the awareness of individuals, encourage non-verbal communication, analyze interpersonal relationships, unify mind and body and get in touch with the spiritual side, expressing this unpretentious spirit in the here and now.

Both in acting and direction, the comprehension and practice of these characteristics is the way to reach self-consciousness. In the case of actors, it allows a greater immersion in the role's demands because personal problems are better identified and consequently discussed and solved. In the case of the director, it allows instructions and feelings about the work and the performances to be communicated objectively, without the interference of poorly resolved personal content.

Schutz (1978) further elaborates that an individual in complete consciousness chooses the most beneficial actions to himself/herself and that a group of fully conscious organisms form the 
most satisfactory society. Or, in the context of cinema, the most satisfying collaborative team and artwork.

Mindfulness captures a quality of consciousness characterized by clarity and vividness of current experience and may be important in disengaging the subject from unhealthy automatic thoughts, habits, and behavioral patterns. (Brown and Ryan, 2003) Since there is no place in art for generic theatrical conventions commonly used by amateurs, the ultimate goal is to put oneself in a creative state in which the subconscious functions naturally. When this is achieved, the eyes of one's soul are opened and the actor becomes alert to everything, even minimal details. He/she becomes aware of new feelings, conceptions, visions and attitudes in his/her role and in himself/herself. (Stanislavski, 2015)

However, focusing on the present setting alone may not be enough, because the energy in a set can be a distraction. Directors can help their actors by understanding and demonstrating that the atmosphere on the set has a determining effect on group performance. The director should try to create an environment that says, "We're all in this together." This greatly relieves tension. (Salvi, 2003)

Given the intimacy of the actor-director relationship, the idea of an actor putting himself/herself in a state of increased consciousness means a greater compromise with the role and the project. Consequently, this generates a better connection among the actor, the director, and the latter's vision, since he/she seeks to bring the script to life using the skills of the cast. Furthermore, if the director is in this state of mind, the deep connection initiated by the actor gains a match at the same level, facilitating communication. 


\section{Problems Arising from the Director's Personality}

Not all the unpleasant situations in a film set are caused by factors arising on the set itself. As the actor may have a problematic and difficult personality to work with, it is quite possible that the director brings his own baggage of problems.

When the director's ego limits his/her vision to a single possible interpretation of the material, the result is an empty performance. Even if every production needs a strong vision behind, the original idea can still be complemented and deepened. (Salvi, 2003) If a criticism or suggestion is acceptable and constructive, Rabiger (2008) recommends that it be recognized and embraced without guilt. The author states that a wise director tries to stimulate the creativity of the important people on the team, aware that changes are inevitable and will always threaten someone's security. But in the case of incompatible suggestions, this fact should be communicated as objectively as possible. Keeping an open head it is not accepting all ideas. As Salvi (2003) points out, a strong leader is not synonymous to a tyrant. The director must respect new ideas brought by the cast, but remain clear about his/her own vision.

Another problem is tyranny, which should not be confused with assertiveness, solid leadership, or strong vision. Tyranny means humiliation and embarrassment, blaming the actor for problems on the set for example. Fruit of insecurity and fear of failure, this mentality blocks and diminishes actors. (Salvi, 2003) This affirmation is in agreement with Rosenberg (2006), who states that the desire to maintain a tough image is caused by a fear of losing authority or control.

Fear of actors is also a ramification of the director's insecurity. Despite the popular image of the director as an all-powerful person, Salvi (2003) points out that it is common for a director to be afraid of his/her cast, scared of intervening. In an environment of inactivity, reluctance and hesitation, the actors soon turn to their colleagues and to themselves and become their own directors. 
Narcissism, often linked to art, has it its share of complications. In this case, the individual is more passionate about the idea of being a director than about the art of directing. Narcissism can fuel early needs and might have led the person to seek art, but must be overcome when responsibility for the work is assumed. (Salvi, 2003) This last aspect is essential in the view of Kazan (2009), who states that to work in films, one must immediately accept total responsibility.

Manipulation, although one of the pillars of film directing, must also be considered from another point of view: when it becomes personal. The path taken should benefit the team as a whole, not the director's selfish needs. (Salvi, 2003)

One way of fixing these traits is by looking at oneself and being frank in the analysis of possible problematic aspects of one's own personality. However, this process should not be carried out without help. Yalom (2006) cites personal psychotherapy as one of the most important aspects of the formation of a group therapist. Self-knowledge has a very important role in recognizing personal distortions, blind spots and fantasies. If these characteristics remain hidden, they can profoundly limit the professional effectiveness. The group therapist, as well as the film director, is a central figure in a network of interpersonal relations. In both cases, it is important that the professional knows himself/herself well and how to identify personal aspects that may complicate his/her professional life, whether it is in psychology or cinema.

\section{Closing Remarks}

Film directing is not about the name that appears in the credits. Essentially, it involves the cooperative efforts of dozens of people towards a goal. The director is responsible for the story, with which he/she has a commitment to honor its themes and truly represent them. 
The director has a central position in a film production. Any problems that arise are his responsibility because they arose under his/her supervision; and if they did without his/her knowledge, it is still his/her fault for it was his/her task to coordinate ideas and ensure that they were in consonance with his/her vision. However, these are management issues of an impersonal nature. He/she must not forget that a considerable part of his/her work involves a relationship with the people on his team. The director never gets to deal with everyone at the same time because it is unfeasible, given the number of people working on a film. There is a well-defined hierarchy to determine who responds to whom and what the responsibilities of each are. Even so, the director remains in charge of dealing with people whose work are crucial to get the job done.

It is with them that deeper relationships are created and with them that difficulties arise. This work aimed to highlight the importance of communication between the director and his/her team, how it can both benefit the project and be an invisible enemy that ends all successes. Among the phenomena, empathy is elemental in building any genuine relationship. Whether therapeutic or professional, there is always a strong sentimental side involved when the doors of the psyche are opened to the content brought by other people. Once a sincere connection of trust is established, the instructions passed by the director can be better absorbed, as long as these are based on objectivity and the principles of efficient feedback.

Moreover, mindfulness fits with the theory of Konstantin Stanislavski as a possible facilitator of the mental state idealized by the author, in which inspiration and creativity are active elements. If the director himself/herself is in a state of mindfulness, he/she will be even more sensitive to his/her environment, sometimes being able to unearth problems erroneously considered non-existent.

As for the problems that arise from the director's personality, these can be better known, understood, and solved through psychotherapy. It provides self-knowledge and facilitates, 
therefore, involvement with actors in general, especially to those rated as neurotic and difficult. By knowing what is within oneself, one can best see others.

While a number of subjects and areas of knowledge are recommended for the intellectual formation of the director, the use of intuition and personal relationships remains fundamental. This illustrates the duality of a work that involves both technical and personal notions. A complete training is related to knowing where to put the camera and why, to recognizing the value of a good script and its potential to become a great film; to knowing various subjects that make art an expression of human nature; and finally to recognizing that the people involved in a production are human beings with the same humanity that is the field of work of every artist.

\section{BIBLIOGRAPHY}

Brown, K. W., And Richard M. Ryan. (2003) The Benefits Of Being Present: Mindfulness And Its Role In Psychological Well-Being. Journal Of Personality And Social Psychology. 4.

Glebas, F. (2009) Directing The Story: Professional Storytelling And Storyboarding Techniques For Live Action And Animation. Burlington: Focal Press.

Jung, C. G. (2011) O Eu E O Inconsciente. Petrópolis: Vozes. Kindle.

Jung, C. G. (1954) The Practice Of Psychotherapy: Essays On The Psychology Of The Transference And Other Subjects. New York: Pantheon Books.

Kazan, E. (2009) Kazan On Directing. New York: Anchor Books. Kindle.

Moscovici, F. (1997) Desenvolvimento Interpessoal: Treinamento Em Grupo. Rio De Janeiro: José Olympio.

Rabiger, M. (2008) Directing: Film Techniques And Aesthethics. Oxford: Focal Press. 
Rosenberg, M. B. (2006) Comunicação Não-Violenta: Técnicas Para Aprimorar Relacionamentos Pessoais E Profissionais. São Paulo: Ágora.

Salvi, D. (2003) Friendly Enemies: Maximizing The Director-Actor Relationship. New York: Billboard Books.

Schutz, W. C. (1978) Psicoterapia Pelo Encontro: Um Guia Para A Conscientização Humana. São Paulo: Atlas.

Stanislavski, K. (2015) An Actor Prepares. South Carolina: Aristophanes Press. Kindle.

Yalom, I. D. (2006) Psicoterapia De Grupo: Teoria E Prática Porto Alegre: Artmed. 